\title{
Physical activity disparities by socioeconomic status among metabolic syndrome patients: The Fifth Korea National Health and Nutrition Examination Survey
}

\author{
Hyo Lee ${ }^{1, *}$, Byung-Hoon Kim² \\ 'Department of Sport and Health Science, Sangmyung University, Seoul, Korea \\ 2Department of Physical Education, Sangmyung University, Seoul, Korea
}

Physical activity plays an important role in preventing further progression of metabolic syndrome conditions to cardiovascular disease and type-2 diabetes. This study investigated physical activity disparities by socioeconomic status among metabolic syndrome patients. The fifth Korea National Health and Nutrition Examination Survey (2010-2012) data were analyzed $(n=19,831)$. A revised definition of the US National Cholesterol Education Program Adult Treatment Panel III was used for screening metabolic syndrome patients. Using International Physical Activity Questionnaire, physical activity adherence was defined as participating in $150+$ minutes of moderate-intensity physical activity, $75+$ minutes of vigorous-intensity physical activity, or an equivalent combination of moderate- to vigorous-intensity physical activity per week. Socioeconomic status was measured by level of education and household income. Among metabolic syndrome patients, physical activity ad- herence rate of first (lowest), second, third, and fourth quartile household income group were $28.31 \%$ (95\% confidence interval [CI], 26.14$30.28 \%), 34.68 \%(95 \% \mathrm{Cl}, 32.71-36.70), 37.44 \%$ (95\% Cl, 35.66-39.25), and $43.79 \%$ (95\% Cl, 41.85-45.75). Physical activity adherence rate of groups with elementary or lower, middle-school, high-school, and college or higher education degree were $25.17 \%(95 \% \mathrm{Cl}, 22.95-27.54), 38.2 \%(95 \%$ $\mathrm{Cl}, 35.13-41.00), 39.60 \%$ (95\% Cl, 38.24-41.77), and $36.89 \%$ (95\% Cl, 35.77-38.03), respectively. This study found that physical activity adherence rate was lower in socioeconomically disadvantaged metabolic syndrome patients, which may aggravate health inequity status of Korean society.

Keywords: Physical activity adherence, Metabolic syndrome, Health inequity, Socioeconomic status

\section{INTRODUCTION}

The association between physical activity and health is well-established. In line with this, many health institutions developed physical activity guidelines for health. For example, the World Health Organization (WHO; World Health Organization, 2010) suggested that adults participate in at least 150 min of moderate-intensity physical activity, 75 min of vigorous-intensity physical activity, or an equivalent volume of moderate- to vigorous-intensity physical activity per week.

Nevertheless, the proportion of people who participate in the recommended level of physical activity is less than ideal in most developed countries. For example, moderate-intensity physical ac-

tivity guideline adherence rate in 2013 Korea National Health and Nutrition Examination Survey (KNHANES; Ministry of Health and Welfare, 2014) was only $9.0 \%$ and $4.5 \%$ in males and females, respectively. Similarly, accelerometer-measured physical activity adherence rate of US adults was 3.5\% in 2003-2004 National Health and Nutrition Examination Survey (Troiano et al., 2008). Consequently, physical inactivity is a public health burden worldwide. Related to this, Lee et al. (2012) reported that physical inactivity, the fourth leading cause of death, caused $9 \%$ of premature mortality, $6 \%$ of coronary heart disease, and $7 \%$ of type- 2 diabetes in 2008 worldwide.

Metabolic syndrome is a combination of at least three of the cardiovascular disease and type- 2 diabetes risk factors: hyperten-

${ }^{*}$ Corresponding author: Hyo Lee (iD http://orcid.org/0000-0002-9396-9333 Department of Sport and Health Science, Sangmyung University, 20 Hongjimun 2-gil, Jongno-gu, Seoul 03016, Korea

Tel: +82-2-781-7535, Fax: +82-2-2287-0075, E-mail: hyolee@smu.ac.kr

Received: December 21, 2015 / Accepted: January 14, 2016
This is an Open Access article distributed under the terms of the Creative Commons Attribution Non-Commercial License (http://creativecommons.org/licenses/by-nc/4.0/) which permits unrestricted non-commercial use, distribution, and reproduction in any medium, provided the original work is properly cited. 
sion, impaired glucose tolerance, abdominal obesity, elevated triglyceride level, and decreased high-density lipoprotein cholesterol level. In Korea, the number of people with metabolic syndrome increased from 24.9\% to 31.3\% during 1998 and 2007 (Lim et al., 2011). Epidemiologic evidences support the association between physical inactivity and the indicators of metabolic syndrome (Barlow et al., 2006; Durstine et al., 2001; Thorogood et al., 2011). Moreover, physical activity is a necessary component of intervention programs to prevent cardiovascular disease and type2 diabetes for people who already have conditions of metabolic syndrome (Dishman et al., 2013).

Meanwhile, Wilkinson (2002) insisted that the prevalence of noncommunicable chronic diseases is associated with economic equity of the society. Korean economic equity has decreased since late 1990's national monetary crisis (Kim and Han, 2007). Accordingly, inequity in metabolic syndrome prevalence among Korean women had increased in 2005 compared to 1998 (Kim and Kim, 2007). Moreover, research shows that socioeconomically disadvantaged groups in Korea are more vulnerable to chronic diseases compared to better socioeconomic group. For example, Kim and $\operatorname{Kim}$ (2007) reported that the incident rate of metabolic syndrome was 38\%-85\% higher in less educated women compared to their counterparts with higher education.

Among many behavioral risk factors, physical inactivity may explain some mechanisms by which socioeconomic inequity affect health disparities. Research on physical activity disparities showed that people in lower socioeconomic class are generally less likely to participate in health-enhancing physical activity. This means that different socioeconomic groups take advantage of different levels of physical activity resources such as knowledge, motivation, and social and physical environment. Moreover, physical inactivity increases chances for not only onset of chronic diseases, but also recurrence and/or further development of such conditions (Kang, 2015). Therefore, it can be a double-difficulty for lower socioeconomic class with hypokinetic chronic diseases such as metabolic syndrome, because they may be less likely to participate in physical activity as a treatment purpose.

Therefore, this study was purposed to investigate physical activity adherence disparities by socioeconomic status that may exist among metabolic syndrome patients in Korea.

\section{MATERIALS AND METHODS}

\section{Data source}

This study analyzed 2010-2012 KNHANES data. KN-
HANES is a continuous annual surveillance system that consists of demographics, questionnaires, health examination, and laboratory test to assess the health and nutritional status of Korean (Ministry of Health and Welfare, 2014). It uses a complex, multistage, probability sampling design to enable estimations to be representative of Korean population. This study analyzed adult subsamples ( $\geq 18$ yr old) with sociodemographic information, physical activity questionnaire, and health examination data $(\mathrm{n}=19,831)$.

\section{Measures}

Socioeconomic status was measured using education level (elementary graduate or lower vs. middle school graduate vs. high school graduate vs. college graduate or higher) and household income quartiles (Oakes and Kaufman, 2006).

In this study, metabolic syndrome was defined as having three or more of the following conditions (Grundy et al., 2004): elevated fasting glucose ( $\geq 110$ or under treatment), central obesity (waist circumference $\geq 90 \mathrm{~cm}$ for male, $\geq 85 \mathrm{~cm}$ for female), systemic hypertension (systolic blood pressure $>130 \mathrm{mmHg}$ or diastolic blood pressure $>85 \mathrm{mmHg}$ ), elevated triglycerides ( $\geq 150$ $\mathrm{mL} / \mathrm{dL})$, diminished high-density lipoprotein $(\leq 40 \mathrm{~mL} / \mathrm{dL}$ for male, $\leq 50 \mathrm{~mL} / \mathrm{dL}$ for female)

Physical activity adherence was defined as meeting minimum criterion of the WHO's (2010) global physical activity recommendation: 150 min of moderate-intensity physical activity, 75 min of vigorous-intensity physical activity, or an equivalent volume of moderate- to vigorous-intensity physical activity (i.e., 600 METs-min/wk). Physical activity was measured using International Physical Activity Questionnaire (IPAQ; Fogelholm et al., 2006). Validity of Korean version of the questionnaire was established by previous studies (Chun, 2012; Oh et al., 2007).

\section{Statistical analyses}

Prevalence of metabolic syndrome and physical activity adherence rate of Korean were estimated. Sex- and age-group-specific physical activity adherence disparities controlling for age were analyzed using adjusted Wald-test. Statistical significance test for adjusted Wald-test was set at 0.05. Using Stata 12.1 (StataCorp LP., College Station, TX, USA), sampling weights were adjusted for all parameter estimations.

\section{RESULTS}

Korean adults' metabolic syndrome prevalence rate was 32.62\% (95\% CI, 31.64-33.61) in 2010-2012. Physical activity adher- 
ence rate of Korean adult during this period was $36.87 \%$ (95\% CI, 35.75-38.01). Among patients with and without metabolic syndrome, the proportion of people who met the WHO physical activity guideline were $36.28 \%$ (95\% CI, 34.45-38.16) and 37.96\% (95\% CI, 36.64-39.29), respectively. Sex- and age-group-specific metabolic syndrome prevalence rate and metabolic syndrome patients' physical activity adherence rate estimation are presented on Tables 1 and 2, respectively.

Metabolic syndrome patients' physical activity adherence rate of the first (lowest), second, third, and fourth quartile household income group were $28.31 \%$ (95\% CI, 26.14-30.28), 34.68\% (95\% CI, 32.71-36.70), 37.44\% (95\% CI, 35.66-39.25), and $43.79 \%$ (95\% CI, 41.85-45.75), respectively. Controlling for age and sex, adherence rate of the fourth income quartile group was statistically significantly higher than the first $[F(1,551)=9.45, P=0.002]$, second $[F(1,551)=8.64, P=0.003]$, and third quartile income

Table 1. Weighted prevalence rate of metabolic syndrome in Korea during 2010-2012 (n=19,831)

\begin{tabular}{llc}
\hline Age group (yr) & Sex & Prevalence rate (95\% CI) \\
\hline $18-39$ & Male & $26.16 \%(24.05-28.38)$ \\
& Female & $12.02 \%(10.67-13.51)$ \\
$40-64$ & Male & $43.62 \%(41.66-45.6)$ \\
& Female & $34.59 \%(32.86-36.37)$ \\
$>64$ & Male & $39.45 \%(36.36-42.63)$ \\
& Female & $60.47 \%(57.92-62.96)$ \\
\hline
\end{tabular}

$\mathrm{Cl}$, confidence interval. groups $[F(1,551)=6.15, P=0.013]$. This means that metabolic syndrome patients with higher income were more likely to adhere to the physical activity guidelines. Physical activity adherence rate of metabolic syndrome patients with elementary or lower, middle-school, high-school, and college or higher education degree were $25.17 \%$ (95\% CI, 22.95-27.54), 38.20\% (95\% CI, 35.1341.00), 39.60\% (95\% CI, 38.24-41.77), and 36.89\% (95\% CI, 35.77-38.03), respectively. Controlling for age and sex, adherence rate of the least educated group was statistically significantly lower than middle school $[F(1,551)=13.55, P<0.001]$, high school $[F(1$, $551)=11.31, P<0.001]$, and college or higher education degree groups $[F(1,551)=8.00, P=0.005]$. This shows that disadvantaged social group in terms of education were less likely to meet the minimum levels of the physical activity guidelines. Sex- and age-group-specific physical activity adherence rate by income and education level is presented on Tables 3 and 4, respectively.

Table 2. Weighted physical activity adherence rate among metabolic syndrome patients in Korea during 2010-2012 ( $n=5,935)$

\begin{tabular}{llc}
\hline Age group (yr) & Sex & Adherence rate $(95 \% \mathrm{CI})$ \\
\hline $18-39$ & Male & $45.13 \%(40.41-49.95)$ \\
& Female & $32.38 \%(26.72-38.62)$ \\
$40-64$ & Male & $44.33 \%(41.25-47.45)$ \\
& Female & $31.90 \%(28.8-35.17)$ \\
$>64$ & Male & $30.14 \%(25.85-34.81)$ \\
& Female & $19.68 \%(17.02-22.64)$ \\
\hline
\end{tabular}

$\mathrm{Cl}$, confidence interval.

Table 3. Estimations of physical activity adherence rate by household income quartile

\begin{tabular}{llccccc}
\hline \multirow{2}{*}{ Age group (yr) } & Sex & \multicolumn{4}{c}{ Adherence rate (95\% confidence interval) } & Adjusted Wald-test \\
\cline { 3 - 6 } & & 1st Quartile (G1) & 2nd Quartile (G2) & 3rd Quartile (G3) & 4th Quartile (G4) \\
\hline \multirow{2}{*}{$18-39$} & Male & $33.65 \%(19.29-51.85)$ & $44.88 \%(35.72-54.40)$ & $46.87 \%(38.85-55.06)$ & $46.00 \%(37.29-54.97)$ & \\
& Female & $34.53 \%(19.94-52.76)$ & $37.38 \%(26.84-49.28)$ & $29.19 \%(20.01-40.46)$ & $27.79 \%(17.52-41.08)$ & \\
$40-64$ & Male & $46.17 \%(36.05-56.62)$ & $41.22 \%(34.61-48.17)$ & $43.20 \%(35.11-45.76)$ & $49.89 \%(45.03-54.75)$ & G2, G3<G4 \\
& Female & $26.10 \%(20.69-32.35)$ & $26.91 \%(21.98-32.48)$ & $34.90 \%(29.34-40.9)$ & $40.27 \%(34.09-46.78)$ & G1, G2<G3, G4 \\
& Male & $29.13 \%(23.55-35.42)$ & $28.40 \%(21.23-36.86)$ & $32.22 \%(21.80-44.77)$ & $35.78 \%(22.62-51.49)$ & \\
& Female & $21.12 \%(17.59-25.14)$ & $17.71 \%(12.52-24.44)$ & $14.07 \%(9.14-21.05)$ & $22.71 \%(15.47-32.05)$ & G1<G3, G4 \\
\hline
\end{tabular}

Table 4. Estimations of physical activity adherence rate by education level

\begin{tabular}{|c|c|c|c|c|c|c|}
\hline \multirow{2}{*}{ Age group (yr) } & \multirow{2}{*}{ Sex } & \multicolumn{4}{|c|}{ Adherence rate ( $95 \%$ confidence interval) } & \multirow{2}{*}{ Adjusted Wald- test } \\
\hline & & Elementary or less (G1) & Middle school (G2) & High school (G3) & College or higher (G4) & \\
\hline $18-39$ & $\begin{array}{l}\text { Male } \\
\text { Female }\end{array}$ & $\begin{array}{l}45.52 \%(4.77-93.31) \\
59.96 \%(13.77-93.35)\end{array}$ & $\begin{array}{l}53.35 \%(23.68-80.83) \\
62.27 \%(33.25-84.54)\end{array}$ & $\begin{array}{l}47.70 \%(39.69-55.82) \\
29.01 \%(22.02-37.17)\end{array}$ & $\begin{array}{l}42.78 \%(36.78-49.00) \\
31.65 \%(23.52-41.08)\end{array}$ & $\mathrm{G} 3<\mathrm{G} 2$ \\
\hline $40-64$ & $\begin{array}{l}\text { Male } \\
\text { Female }\end{array}$ & $\begin{array}{l}32.76 \%(25.67-40.74) \\
25.17 \%(20.94-29.93)\end{array}$ & $\begin{array}{l}41.50 \%(34.20-49.19) \\
37.16 \%(30.63-44.18)\end{array}$ & $\begin{array}{l}45.77 \%(40.71-50.92) \\
35.97 \%(30.41-41.93)\end{array}$ & $\begin{array}{l}48.48 \%(43.08-53.91) \\
31.63 \%(23.60-40.94)\end{array}$ & $\begin{array}{l}\mathrm{G} 1<\mathrm{G} 3, \mathrm{G} 4 ; \mathrm{G} 2<\mathrm{G} 4 \\
\mathrm{G} 1<\mathrm{G} 2\end{array}$ \\
\hline$>64$ & $\begin{array}{l}\text { Male } \\
\text { Female }\end{array}$ & $\begin{array}{l}28.62 \%(22.58-35.53) \\
19.39 \%(16.43-22.74)\end{array}$ & $\begin{array}{l}21.61 \%(14.35-31.20) \\
22.10 \%(14.08-32.95)\end{array}$ & $\begin{array}{l}33.32 \%(25.32-42.43) \\
21.52 \%(12.63-34.21)\end{array}$ & $\begin{array}{l}42.36 \% \text { (29.26-56.63) } \\
13.88 \% \text { (4.82-33.88) }\end{array}$ & $\mathrm{G} 2<\mathrm{G} 4$ \\
\hline
\end{tabular}




\section{DISCUSSION}

This study investigated disparities in physical activity adherence rate among metabolic syndrome patients using 2010-2012 KNHANES data. Overall, it was found that physical activity inequity by income and education level does exist among metabolic syndrome patients. Also, there were sex- and age-group-differences in the inequity patterns.

As shown in Table 1, metabolic syndrome prevalence rate was higher in older groups compared to younger counterparts, and such trend was stronger in females than males. Even though physical activity is important to prevent progression of cardiovascular disease and type-2 diabetes in these population, adherence rate to the WHO physical activity recommendation is far less than ideal (31.90\%-44.33\% among middle-age group; $19.68 \%-30.14 \%$ among older adults). The implication of this finding is twofold: (a) physical inactivity may contribute to increased metabolic syndrome prevalence; and (b) patients with metabolic syndrome do not participate in the generally recommended amount physical activity for health.

Sex- and age-group-specific analyses of physical activity disparities by household income and education level (Tables 3 and 4) suggest that lower income groups of middle age (40-64 yr old) and older group's (64 yr old or older) adherence rate were significantly lower than higher income and/or education groups. Among younger adults (18-39 yr old), such trend was not clearly observable or significant. On the contrary, young female adults' physical activity adherence rate was lower in better educated groups. Elementary and middle school education has been mandatory in Korea since 1985, so very small fraction of population belong to "elementary or less" ( $\mathrm{n}=18,0.36 \%)$ and "middle school" $(\mathrm{n}=3.61 \%)$ category in this age group. This may have contributed to the inflated standard error of estimation of the adherence rate in these subgroups. Readers should consider this when interpreting the results in the young adult group.

Research on health inequity showed that socioeconomic inequity affects onset of chronic diseases (Kim and Kim, 2007; Lim et al., 2011). This study added to the past research findings that physical activity as a treatment of such conditions to prevent further development may be unequal across different socioeconomic groups. Future study should further explore psychosocial and biological mechanisms by which physical activity disparities affect incidence rates of cardiovascular diseases and type- 2 diabetes among metabolic syndrome patients.

Meanwhile, research has shed lights on health disparities in de- veloped countries, because it is an important index of social justice (Kim and Kim, 2007). Health inequity directly affects health status of lower socioeconomic group of a society by lower quality of built and social environment, elevated behavioral risk factors, limited access to health care system, and psychological stress (Berkman et al., 2014). Declined social welfare causes social conflict, psychosocial stress, and consequently health status of the whole society members (Wilkinson, 2002). Therefore, not only lower but also higher socioeconomic groups may be at risk for chronic diseases when socioeconomic equity is impaired.

According to Kim and Kim (2007), socioeconomic disparities in Korean adults affected not only health outcomes but also health behaviors as mediators by which such social conditions affect health outcomes. According to Yang et al. (2005), in addition, there were differences in Korean adults' physical activity level by their socioeconomic status in 2001. The current study findings suggest that physical activity disparities have not been alleviated during 2001-2012. Therefore, reducing health inequity by promoting physical activity in lower socioeconomic group is still a public health priority.

Limitations of this study include cross-sectional survey design, subjective measure of physical activity, and relatively simplistic measure of socioeconomic status. Due to cross-sectional design, this study results do not support cause-and-effect inferences. IPAQ is a 7-day recall subjective measure of physical activity, which is vulnerable to recall bias and social justice bias. Also, IPAQ does not capture physical activity of daily life, but to what extent the participant was physically active during the past 7 days. Measures of socioeconomic class in recent studies in health sociology include not only income and education but also community-based indicators such as quality of living place (Berkman et al., 2014). Future studies should consider using improved study designs and measures.

\section{CONFLICT OF INTEREST}

No potential conflict of interest relevant to this article was reported.

\section{ACKNOWLEDGMENTS}

This research was supported by a 2013 research grant from Sangmyung University. 


\section{REFERENCES}

Barlow CE, LaMonte MJ, Fitzgerald SJ, Kampert JB, Perrin JL, Blair SN. Cardiorespiratory fitness is an independent predictor of hypertension incidence among initially normotensive healthy women. Am J Epidemiol 2006;163:142-150.

Berkman LF, Kawachi I, Glymour MM, editors. Social epidemiology. Oxford: Oxford University Press; 2014.

Chun MY. Validity and reliability of korean version of international physical activity questionnaire short form in the elderly. Korean J Fam Med 2012;33:144-151.

Dishman, RK, Heath G, Lee IM. Physical activity epidemiology, 2nd ed. Champaign (IL): Human Kinetics; 2013.

Durstine JL, Grandjean PW, Davis PG, Ferguson MA, Alderson NL, DuBose KD. Blood lipid and lipoprotein adaptations to exercise: a quantitative analysis. Sports Med 2001;31:1033-1062.

Fogelholm M, Malmberg J, Suni J, Santtila M, Kyröläinen H, Mäntysaari M, Oja P. International physical activity questionnaire: validity against fitness. Med Sci Sports Exerc 2006;38:753-60.

Grundy SM, Brewer HB Jr, Cleeman JI, Smith SC Jr, Lenfant C; American Heart Association; National Heart, Lung, and Blood Institute. Definition of metabolic syndrome: Report of the National Heart, Lung, and Blood Institute/American Heart Association conference on scientific issues related to definition. Circulation 2004;109:433-438.

Kang SJ. The association of physical activity and colorectal and breast cancer: The Fifth Korea National Health and Nutrition Examination Survey (2008-2011). J Exerc Rehabil 2015;11:155-160.

Kim YM, Han J. Changes in income inequality after the financial crisis decomposition of income inequality, 1998-2005. Korean J Sociol 2007;41:35-63.

Kim YM, Kim MH. Health inequalities in Korea: current conditions and implications. J Prev Med Public Health 2007;40:431-438.

Ministry of Health and Welfare. National Health and Nutrition Examination Survey Report 2013. Sejong: Ministry of Health and Welfare; 2014

Lee IM, Shiroma EJ, Lobelo F, Puska P, Blair SN, Katzmarzyk PT; Lancet Physical Activity Series Working Group. Effect of physical inactivity on major non-communicable diseases worldwide: an analysis of burden of disease and life expectancy. Lancet 2012;380:219-229.

Lim S, Shin H, Song JH, Kwak SH, Kang SM, Won Yoon J, Choi SH, Cho SI, Park KS, Lee HK, Jang HC, Koh KK. Increasing prevalence of metabolic syndrome in Korea: the Korean National Health and Nutrition Examination Survey for 1998-2007. Diabetes Care 2011;34:1323-1328.

Oakes JM, Kaufman JS, editors. Methods in social epidemiology. San Francisco (CA): Jossey-Bass; 2006.

Oh JY, Yang YJ, Kim BS, Kang JH. Validity and Reliability of Korean Version of International Physical Activity Questionnaire (IPAQ) Short Form. J Korean Acad Fam Med 2007;28:532-541.

Thorogood A, Mottillo S, Shimony A, Filion KB, Joseph L, Genest J, Pilote L, Poirier P, Schiffrin EL, Eisenberg MJ. Isolated aerobic exercise and weight loss: a systematic review and meta-analysis of randomized controlled trials. Am J Med 2011;124:747-755.

Troiano RP, Berrigan D, Dodd KW, Mâsse LC, Tilert T, McDowell M. Physical activity in the United States measured by accelerometer. Med Sci Sports Exerc 2008;40:181-188.

Wilkinson RG. Unhealthy societies: the afflictions of inequality. London: Routledge; 2002.

World Health Organization. Global recommendations on physical activity for health. Geneva: World Health Organization; 2010.

Yang YJ, Yoon YS, Oh SW, Lee ES. The amount of physical activity of Korean adults measured from the 2001 Korean National Health and Nutrition Survey. J Korean Acad Fam Med 2005;26:22-30. 